\title{
THE INFLUENCE OF FINNISH SAUNA TREATMENTS ON THE CONCENTRATIONS OF NITRIC OXIDE, 3-NITROTYROSINE AND SELECTED MARKERS OF OXIDATIVE STATUS IN TRAINING AND NON-TRAINING MEN
}

\section{DOROTA GRYKA ${ }^{1}$, WANDA PILCH ${ }^{2}$, OLGA CZERWIŃSKA-LEDWIG ${ }^{2}$, ANNA PIOTROWSKA ${ }^{2}$, EWA KLOCEK ${ }^{3}$, and ALENA BUKOVA ${ }^{4}$}

${ }^{1}$ University of Physical Education, Kraków, Poland

Faculty of Physical Education and Sport, Department of Physiology and Biochemistry

${ }^{2}$ University of Physical Education, Kraków, Poland

Faculty of Rehabilitation

${ }^{3}$ University of Physical Education, Kraków, Poland

Faculty of Physical Education and Sport

${ }^{4}$ Pavol Jozef Šafárik University in Košice, Košice, Slovakia

Institute of Physical Education and Sport

\begin{abstract}
Objectives: The aim of the study was to evaluate the effects of repeated Finnish sauna baths on the concentrations of nitric oxide metabolites $\left(\mathrm{NO}_{\mathrm{x}}\right)$ and 3-nitrotyrosine in relation to pro-oxidative and antioxidative status in young males with different physical activity levels. Material and Methods: The study was performed on healthy males (aged 20-25 years), representing the training $(\mathrm{T}, \mathrm{N}=10)$ and non-training groups $(\mathrm{NT}, \mathrm{N}=10)$. The protocol included a series of 10 sauna baths during 3 weeks. One bath consisted of three 15-min sessions, with 2 min recovery. Before the first and the 10th treatment, measurements of body composition, blood pressure, rectal temperature, and plasma concentrations of the total pro-oxidative and antioxidative status, 3-nitrotyrosine and $\mathrm{NO}_{\mathrm{x}}$ were performed. Results: A significant increase in physiological parameters during sauna treatments, as well as a significant decrease in the total antioxidative status before the 10th bath, were observed in both groups. The series of sauna baths caused a significant increase in the total antioxidative status in the T group, and a decrease in the total oxidative status in the NT group. A significant decrease in 3-nitrotyrosine in both groups before the last treatment, and also in the T group after the last treatment, was noted. In both groups, a significant increase in $\mathrm{NO}_{\mathrm{x}}$ concentrations was observed after the first bath. Conclusions: A series of sauna baths contributes to the improvement in the prooxidative/antioxidative balance. The increased production of nitric oxide may lead to a better vascular relaxation and blood flow. Int J Occup Med Environ Health. 2020;33(2):173-85
\end{abstract}

Key words:

oxidative stress, nitric oxide, 3-nitrotyrosine, nitrosative stress, Finnish sauna, training and non-training men

Funding: this study was supported by the University of Physical Education, Kraków, Poland (grant No. 92/BS/KF/2016 entitled "The impact of a series of treatments in a Finnish sauna on selected oxidative stress indicators, nitric oxide synthase (eNOS) activity and the level of vascular endothelial growth factor (VEGF) in young men," grant manager: Prof. Wanda Pilch).

Received: July 8, 2019. Accepted: November 13, 2019.

Corresponding author: Anna Piotrowska, University of Physical Education, Faculty of Rehabilitation, Al. Jana Pawła II 78, 31-571 Kraków, Poland (e-mail: anna.piotrowska@awf.krakow.pl). 


\section{INTRODUCTION}

Nitric oxide (NO) is synthesized by 3 separate isoforms of synthase (nitric oxide synthase - NOS) - 2 consecutive forms: neuronal (nNOS) and endothelial (eNOS), which depend on calcium ions and calmodulin, and 1 inducible form (iNOS), stimulated mostly by cytokines and lipopolysaccharides. In physiological conditions, NO is formed in endothelial cells with eNOS, and it activates cyclic guanosine monophosphate (cGMP)-dependent phosphatase which causes dephosphorylation of light chains of myosin, relaxation of smooth muscles and dilation of blood vessels [1]. In pathological conditions, such as inflammation, NO is formed with iNOS. The consequence of this process is an excessive activation of cyclooxygenase (COX), which can lead to the formation of superoxide radical $\left(\mathrm{O}_{2}{ }^{-}\right)$and large quantities of proinflammatory prostaglandins [2]. Superoxide radical in reaction with NO gives highly toxic peroxynitrite $\left(\mathrm{ONOO}^{-}\right)$. This radical induces the peroxidation of membrane lipids and deactivation of a series of protein chains/enzymes as a result of nitration of tyrosine residues [3]. The 3-nitrotyrosine $\left(\mathrm{NO}_{2}-\mathrm{Tyr}\right)$ is formed in the reaction of amino acid nitration and is considered a marker of nitrosative stress [4]. The final products of $\mathrm{NO}$ metabolism are nitrites $\left(\mathrm{NO}^{2-}\right)$ and nitrates $\left(\mathrm{NO}^{3-}\right)$ [5] which are present in serum in variable proportions. Therefore, the best method to evaluate the production of NO is to measure the total amount of both metabolites.

Finnish sauna treatments are a widespread form of athletic recovery [6-8] using the contrast of thermal stimulus. The results of already published studies confirm the beneficial effect of sauna baths on the cardiovascular system [9-11], recovery after exercise [11,12], immunity [9], or general well-being $[11,13]$. However, the available thematic literature offers a very few positions presenting the influence of a series of dry sauna treatments on the blood pro-oxidative and antioxidative status, with special consideration of nitrosative stress in humans $[12,14]$. These studies inspired the authors to undertake the research de- scribed in this paper. Its aim was to evaluate the effects of repeated treatments in the Finnish sauna on the concentrations of nitric oxide metabolites $\left(\mathrm{NO}_{\mathrm{x}}\right)$ and 3-nitrotyrosine in relation to pro-oxidative and antioxidative status in young males with different physical activity levels.

\section{MATERIAL AND METHODS}

\section{Study participants}

The study was performed in 2 groups of healthy males aged 20-25 years. The training group $(\mathrm{T}, \mathrm{N}=10)$ included runners who had been training for $5 \pm 1.5$ years, running middle and long distances as members of the Academic Sports Association. The study took place in October-December, when the runners were in the detraining period, 2 months after the last competition and/or training. The non-training group $(\mathrm{NT}, \mathrm{N}=10)$ consisted of volunteers whose physical activity, estimated with the International Physical Activity Questionnaire (IPAQ) [15], was at a medium level (category 2). The other inclusion criteria for participation in the study were as follows: no disturbances in the results of complete blood count $(\mathrm{CBC})$ and electrocardiogram (ECG), and no acute infection or symptoms of chronic diseases, like arterial hypertension, diabetes, and epilepsy. The study participants from both groups had not attended sauna sessions before.

The anthropometric characteristics of the study participants from both groups are listed together in Table 1.

Before participating in the study, in accordance with the requirements of the Declaration of Helsinki, all the subjects were informed about the objective and methodology of the research project, the possible side effects, and the fact that they were allowed to resign from participation in the study at any time without stating the cause. The subjects were also informed about the necessity of not modifying their daily diets, not taking dietary supplements and not consuming alcohol. The study project was approved by the Bioethics Commission by the Re- 
Table 1. Somatic parameters of the participants in the study on the influence of Finnish sauna baths on the concentrations of nitric oxide metabolites $\left(\mathrm{NO}_{x}\right)$ and 3-nitrotyrosine $\left(\mathrm{NO}_{2}-\mathrm{Tyr}\right)$ in relation to pro-oxidative and antioxidative status of 2 groups of healthy males

\begin{tabular}{|c|c|c|}
\hline \multirow[t]{2}{*}{ Variable } & \multicolumn{2}{|c|}{$\begin{array}{l}\text { Participants } \\
(\mathrm{N}=20) \\
(\mathrm{M} \pm \mathrm{SD})\end{array}$} \\
\hline & $\begin{array}{l}\text { training group } \\
\quad(\mathrm{N}=10)\end{array}$ & $\begin{array}{l}\text { non-training group } \\
\qquad(\mathrm{N}=10)\end{array}$ \\
\hline Age [years] & $20.80 \pm 0.79$ & $20.20 \pm 0.93$ \\
\hline Body height [m] & $1.81 \pm 0.04$ & $1.82 \pm 0.06$ \\
\hline Body mass [kg] & $73.43 \pm 8.36$ & $77.78 \pm 11.35$ \\
\hline Body mass index $\left[\mathrm{kg} / \mathrm{m}^{2}\right]$ & $22.37 \pm 1.75$ & $23.51 \pm 2.28$ \\
\hline \multicolumn{3}{|l|}{ Fat } \\
\hline$\%$ & $9.36 \pm 1.81$ & $12.06 \pm 3.96$ \\
\hline $\mathrm{kg}$ & $6.98 \pm 1.96$ & $9.70 \pm 4.63$ \\
\hline Lean body mass [kg] & $66.45 \pm 6.65$ & $68.07 \pm 7.38$ \\
\hline
\end{tabular}

gional Medical Chamber in Krakow (66/KBL/OIL/2011). All the participants gave their written consent to participate in the study.

\section{Experimental procedure}

The study protocol included a series of 10 baths in the traditional Finnish (dry) sauna. Each of the 10 treatments consisted of three 15-min sessions in the sauna chamber, between which the body was cooled down for 2 min with running water of approx. $20^{\circ} \mathrm{C}$. The mean temperature in the sauna chamber at the head level was $90 \pm 2^{\circ} \mathrm{C}$, and relative humidity of the air was $5-16 \%$. The participants were not allowed to change their sitting place in the sauna chamber. They were asked to take seats in the upper part of the chamber, where air temperature was measured. The sessions took place before noon. The subjects participated in them in fasting conditions (at least $8 \mathrm{~h}$ after the last meal). They were allowed to drink 0.51 of water in the morning, before the treatment. The subjects went into the sauna chamber without clothes and they did not drink anything during the session. Intervals between the treatments were 1 or 2 days (weekends). For each par- ticipant, the program of sauna sessions lasted 3 weeks. All the treatments were supervised by a physician.

\section{Anthropometric measures}

Before the first and the 10th treatment, the following parameters were measured: body weight of the subjects with scales type F1505-DZA manufactured by Sartorius (Germany), with the accuracy of up to $1 \mathrm{~g}$, body height with a medical scales indicator, with the accuracy to $1 \mathrm{~cm}$, blood pressure (systolic blood pressure / diastolic blood pressure - SBP/DBP) with a mercury sphygmomanometer, with the accuracy of up to $5 \mathrm{~mm} \mathrm{Hg}$, heart rate (HR) with the palpation method, and skinfold thickness with a Harpenden skinfold caliper with a $20 \mathrm{~g}$ pressure strength on the contact surface, with the accuracy of up to $0.1 \mathrm{~mm}$. The percentage of body fat $(\mathrm{PF})$ was calculated in accordance with the formula proposed by Slaughter et al. [16].

Before entering the sauna chamber, rectal temperature measurement sensors were placed $15 \mathrm{~cm}$ deep in the rectum. Rectal temperature $\left(\mathrm{T}_{\mathrm{re}}\right)$ and $\mathrm{HR}$ were taken at 5-min intervals. 


\section{Biochemical analyses}

Blood for biochemical analyses during the first and the last sauna bath was taken 3 times: immediately prior entering the chamber, $10 \mathrm{~min}$ after the bath (the time required for taking a shower and drying the body), and $24 \mathrm{~h}$ after leaving the sauna. In order to obtain a blood serum sample in which the total protein concentration was determined, $5 \mathrm{ml}$ of blood were collected from a vein in the cubital fossa to Vacutainer test tubes with coagulation activator. In addition, $5 \mathrm{ml}$ of blood were collected to test tubes with EDTA, in order to obtain a plasma sample and to perform assays of the total plasma pro-oxidative and antioxidative status (TAS/TAC; TOS/TOC), $\mathrm{NO}_{2}$-Tyr and $\mathrm{NO}_{\mathrm{x}}$. On the days during which blood samples were taken, the subjects were examined in fasting conditions (at least $8 \mathrm{~h}$ after the last meal).

The body dehydration level was estimated based on changes in the total protein concentration $(\% \Delta \mathrm{PV})$, using the formula by Johansen et al. [17]. Due to the dynamic changes in the volume of plasma during the sauna bath, the concentration of the analyzed biochemical parameters from the samples collected after the bath was corrected. To calculate the corrected values, the formula proposed by Kraemer and Brown [18] was used.

In blood plasma, using the colorimetric method, plasma TAS and TOS were measured (Immundiagnostik AG; sensitivity: $130 \mu \mathrm{mol} \times \mathrm{l}^{-1}, 7 \mu \mathrm{mol} \times \mathrm{l}^{-1}$, respectively) and the concentration of $3-\mathrm{NO}_{2}$-Tyr was determined with the use of polyclonal antibodies against nitrotyrosine (Immundiagnostik AG; sensitivity: $14.9 \mathrm{nmol} \times \mathrm{l}^{-1}$ ). The concentration of $\mathrm{NO}_{\mathrm{x}}$ was determined with the Nitrate/Nitrite Colorimetric Assay Kit (Cayman Chemical Company; sensitivity $2.5 \mu \mathrm{mol} \times \mathrm{l}^{-1}$ ). In order to reduce interference between the presence of hemoglobin and NO, plasma was filtered using filters manufactured by Amicon Ultra- 0.5 with a pore size of $10 \mathrm{kDa}$. Then, it was centrifuged in an MPW laboratory centrifuge with a force of $14000 \times 1 \mathrm{~g}$. Finally, $\mathrm{NO}_{\mathrm{x}}$ was assayed by means of the Griess reagent.

\section{Statistical analysis}

Statistical analysis of the results was performed using Statistica 10.0 for Windows software developed by StatSoft. The normality of the distribution of variables was checked with the Shapiro-Wilk test. To compare the significance of differences in the dependent groups, the ANOVA Friedman test, a non-parameter equivalent of the one-reagent variance analysis for repeated measurements, was used; additionally, the data was checked with the Wilcoxon signed-rank test. The significance levels of the differences in mean values between the groups of training and nontraining males were calculated using the Mann-Whitney $\mathrm{U}$ test. To assess the relationship between physiological and biochemical indices, Spearman's rank correlation coefficients were used. In the calculations, the significance level of $p<0.05$ was assumed as statistically significant. All the results are presented in the form of arithmetic mean values: $\mathrm{M} \pm$ standard deviation (SD).

\section{RESULTS}

The physiological parameters measured during monitored treatments, $10 \mathrm{~min}$ before entering the sauna chamber and $10 \mathrm{~min}$ after the end of the sauna bath and the last cooling down of the body, are presented in Table 2. During the monitored sauna treatments, a significant increase $(\mathrm{p}<0.01)$ in HR was observed in both study groups. The mean increase in HR in the subjects was lower during the last sauna bath $(\Delta 2 \mathrm{HR})$ than during the first one $(\Delta 1 \mathrm{HR})$, whereas the statistical significance of this change at the level of $p<0.05$ was recorded only in the group of training subjects. Additionally, in the training group, a significantly lower HR was observed before the 10th sauna bath in comparison to the first one $(p<0.05)$. A significant increase in SBP with a simultaneous decrease in DBP was noted in both study groups $(p<0.01)$ after the first and the last bath. No statistically significant differences between the training and non-training groups were observed in blood pressure. In both study groups, a significant in- 
Table 2. Physiological parameters during the first and 10th bath in the Finnish sauna, in the study on the influence of Finnish sauna baths on the concentrations of nitric oxide metabolites $\left(\mathrm{NO}_{\mathrm{x}}\right)$ and 3-nitrotyrosine $\left(\mathrm{NO}_{2}\right.$-Tyr) in relation to pro-oxidative and antioxidative status of 2 groups of healthy males

\begin{tabular}{|c|c|c|}
\hline \multirow[t]{2}{*}{ Variable/measurement } & \multicolumn{2}{|c|}{$\begin{array}{l}\text { Participants } \\
(\mathrm{N}=20) \\
(\mathrm{M} \pm \mathrm{SD})\end{array}$} \\
\hline & $\begin{array}{l}\text { training group } \\
\quad(\mathrm{N}=10)\end{array}$ & $\begin{array}{l}\text { non-training group } \\
\qquad(\mathrm{N}=10)\end{array}$ \\
\hline \multicolumn{3}{|l|}{ Heart rate $[\mathrm{bpm}]$} \\
\hline \multicolumn{3}{|l|}{ measurement 1} \\
\hline $1 \mathrm{~A}$ & $67.6 \pm 6.1$ & $74.0 \pm 6.9$ \\
\hline $1 \mathrm{~B}$ & $131.6 \pm 5.5^{* *}$ & $136.4 \pm 9.7^{* *}$ \\
\hline$\Delta 1$ & $64.0 \pm 8.4$ & $62.4 \pm 6.9$ \\
\hline \multicolumn{3}{|l|}{ measurement 2} \\
\hline $2 \mathrm{~A}$ & $66.4 \pm 3.4^{\S}$ & $72.0 \pm 5.7$ \\
\hline $2 \mathrm{~B}$ & $124.4 \pm 4.8^{* *}$ & $129.6 \pm 6.3^{* *}$ \\
\hline$\Delta 2$ & $58.0 \pm 6.3^{\#}$ & $57.6 \pm 7.1$ \\
\hline \multicolumn{3}{|l|}{ Systolic blood pressure [mm Hg] } \\
\hline \multicolumn{3}{|l|}{ measurement 1} \\
\hline $1 \mathrm{~A}$ & $124.0 \pm 9.4$ & $116.5 \pm 6.7$ \\
\hline $1 \mathrm{~B}$ & $136.0 \pm 8.8^{* *}$ & $131.5 \pm 8.2^{* *}$ \\
\hline$\Delta 1$ & $12.0 \pm 9.8$ & $15.0 \pm 8.5$ \\
\hline \multicolumn{3}{|l|}{ measurement 2} \\
\hline $2 \mathrm{~A}$ & $119.0 \pm 9.7$ & $114.0 \pm 8.1$ \\
\hline $2 \mathrm{~B}$ & $132.0 \pm 10.3^{* *}$ & $126.0 \pm 8.1 * *$ \\
\hline$\Delta 2$ & $13.0 \pm 9.8$ & $12.0 \pm 9.2$ \\
\hline \multirow{2}{*}{\multicolumn{3}{|c|}{$\begin{array}{l}\text { Diastolic blood pressure [mm Hg] } \\
\text { measurement } 1\end{array}$}} \\
\hline & & \\
\hline $1 \mathrm{~A}$ & $80.0 \pm 4.1$ & $79.5 \pm 4.4$ \\
\hline 1B & $71.0 \pm 7.75^{* *}$ & $69.5 \pm 6.85^{* *}$ \\
\hline$\Delta 1$ & $-9.0 \pm 7.4$ & $-10 \pm 6.7$ \\
\hline \multicolumn{3}{|l|}{ measurement 2} \\
\hline $2 \mathrm{~A}$ & $79.0 \pm 5.7$ & $80.5 \pm 4.4$ \\
\hline $2 \mathrm{~B}$ & $73.0 \pm 7.15^{* *}$ & $72.0 \pm 9.2 * *$ \\
\hline$\Delta 2$ & $-6.0 \pm 5.9$ & $-8.5 \pm 7.9$ \\
\hline \multicolumn{3}{|l|}{ Rectal temperature $\left[{ }^{\circ} \mathrm{C}\right]$} \\
\hline \multicolumn{3}{|l|}{ measurement 1} \\
\hline $1 \mathrm{~A}$ & $37.04 \pm 0.18$ & $37.05 \pm 0.23$ \\
\hline 1B & $38.51 \pm 0.28^{*}$ & $38.66 \pm 0.24 *$ \\
\hline$\Delta 1$ & $1.47 \pm 0.18$ & $1.61 \pm 0.21$ \\
\hline
\end{tabular}


Table 2. Physiological parameters during the first and 10th bath in the Finnish sauna, in the study on the influence of Finnish sauna baths on the concentrations of nitric oxide metabolites $\left(\mathrm{NO}_{\mathrm{x}}\right)$ and 3-nitrotyrosine $\left(\mathrm{NO}_{2}\right.$-Tyr) in relation to pro-oxidative and antioxidative status of 2 groups of healthy males - cont.

\begin{tabular}{|c|c|c|}
\hline \multirow[t]{2}{*}{ Variable/measurement } & \multicolumn{2}{|c|}{$\begin{array}{c}\text { Participants } \\
(\mathrm{N}=20) \\
(\mathrm{M} \pm \mathrm{SD})\end{array}$} \\
\hline & $\begin{array}{l}\text { training group } \\
\quad(\mathrm{N}=10)\end{array}$ & $\begin{array}{l}\text { non-training group } \\
(\mathrm{N}=10)\end{array}$ \\
\hline \multicolumn{3}{|l|}{$\begin{array}{l}\text { Rectal temperature }\left[{ }^{\circ} \mathrm{C}\right]-\text { cont. } \\
\text { measurement } 2\end{array}$} \\
\hline $2 \mathrm{~A}$ & $36.68 \pm 0.27$ & $36.64 \pm 0.32$ \\
\hline $2 \mathrm{~B}$ & $38.09 \pm 0.22^{*}$ & $38.2 \pm 0.22 *$ \\
\hline$\Delta 2$ & $1.41 \pm 0.25$ & $1.56 \pm 0.37$ \\
\hline
\end{tabular}

1 - results during the first bath in the Finnish sauna; 2 - results during the 10th bath in the Finnish sauna; A - before the bath;

$\mathrm{B}-10$ min after the bath; $\Delta$ - differences between measurements (B-A).

$* \mathrm{p}<0.05$ significant changes between $1 \mathrm{~A}$ and $1 \mathrm{~B}, 2 \mathrm{~A}$ and $2 \mathrm{~B}$ in the training and non-training groups.

$* * \mathrm{p}<0.01$ significant changes between $1 \mathrm{~A}$ and $1 \mathrm{~B}, 2 \mathrm{~A}$ and $2 \mathrm{~B}$ in the training and non-training groups.

${ }^{\S} \mathrm{p}<0.05$ significant differences between $1 \mathrm{~A}$ and $2 \mathrm{~A}$ in the training group.

${ }^{\#} \mathrm{p}<0.05$ significant differences between $\Delta 1$ and $\Delta 2$ in the training group.

crease in internal body temperature after the first and the last sauna bath was noted $(\mathrm{p}<0.05)$.

As shown in Figure 1, the level of TAS before the series of treatments did not show any significant differences between the study groups. In the training group, a significant increase in TAS after the 10th bath was observed $(\mathrm{p}<0.05)$, and also a decrease between the values measured before the first bath $(1 \mathrm{~A})$ and $24 \mathrm{~h}(2 \mathrm{C})$ after the last bath $(\mathrm{p}<0.05)$. In both groups, a significant decrease in TAS before the 10 th bath $(\mathrm{p}<0.05)$ was observed.

The 10th bath contributed to a significant decrease in TOS only in the non-training group $(\mathrm{p}<0.05)$ (Figure 2$)$.

The influence of sauna treatments on the concentration of NO in the blood of the subjects is presented in Figure 3. In both groups, a significant increase in the concentrations of NO was observed after the first bath, and the highest concentration was found in the blood collected $24 \mathrm{~h}$ after the last bath $(\mathrm{p}<0.05)$.

As shown in Figure 4, a regular exposure of the organism to thermal stimuli caused a significant decrease in $\mathrm{NO}_{2}$-Tyr in both groups before the last treatment, and in the training group also after the last treatment.

Table 3 presents changes in the volume of plasma. Both the first and the last treatment caused a decrease in the volume of plasma in both groups. The last sauna session caused a greater decrease in the volume of plasma $(\% \Delta \mathrm{PV} 2)$ in the training group than in the non-training group ( $\mathrm{p}<0.01)$. After the series of sauna treatments, an adaptive increase in the volume of plasma $(\% \Delta \mathrm{PV} 3)$ was observed in all the study participants.

\section{DISCUSSION}

The results obtained in this study have shown that a series of 10 baths in the Finnish sauna modulates systemic homoeostasis. This is depicted by the observed reaction of the circulatory system, reflected in the heart rate and blood pressure values. The observed increase in HR should be considered an effect of activating the autonomous nervous system in order to compensate for the vasodilatation and maintain blood pressure $[19,20]$. It is worth 


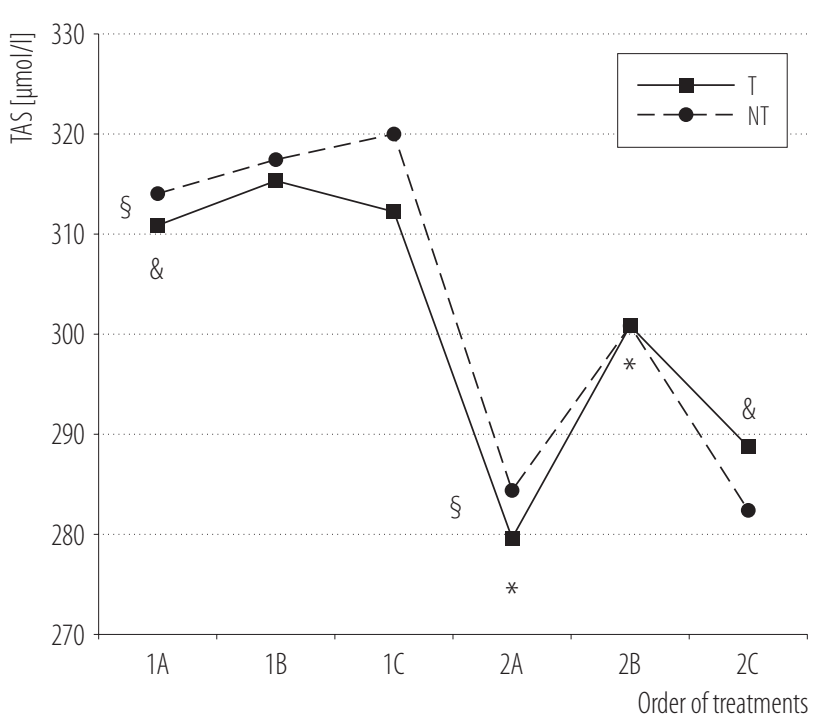

1 - results during the first bath in the Finnish sauna; 2 - results during the 10th bath in the Finnish sauna; A - before the bath; B - 10 min after the bath; $\mathrm{C}-24 \mathrm{~h}$ after the bath.

${ }^{\S} \mathrm{p}<0.05$ significant changes in the training and non-training groups between $1 \mathrm{~A}$ and $2 \mathrm{~A}$ measurements.

${ }^{\&} \mathrm{p}<0.05$ significant changes in the training group between $1 \mathrm{~A}$ and $2 \mathrm{C}$ measurements.

${ }^{*} \mathrm{p}<0.05$ significant changes in the training group between $2 \mathrm{~A}$ and 2B measurements.

Figure 1. Changes in the plasma total antioxidant status (TAS) in the training (T) and non-training groups (NT) during sauna baths, in the study on the influence of Finnish sauna baths on the concentrations of nitric oxide metabolites $\left(\mathrm{NO}_{\mathrm{x}}\right)$ and 3-nitrotyrosine $\left(\mathrm{NO}_{2}-\mathrm{Tyr}\right)$ in relation to pro-oxidative and antioxidative status of 2 groups of healthy males

mentioning that, after the series of sauna treatments, significantly lower HR values were observed before the last bath in the males from the $\mathrm{T}$ group as compared to the NT group. This can suggest a common adaptive effect of long-term athletic training and a better acclimation in high temperatures of the sauna [21-23]. The adaptation can also be indicated by the fact that the change in HR values ( $\Delta 1$ and $\Delta 2)$ was significantly lower during the last treatment, in comparison to the first one. In both groups, an increase in SBP was observed with a simultaneous decrease in DBP, both after the first and the last treatment. These results are consistent with reports by Han-

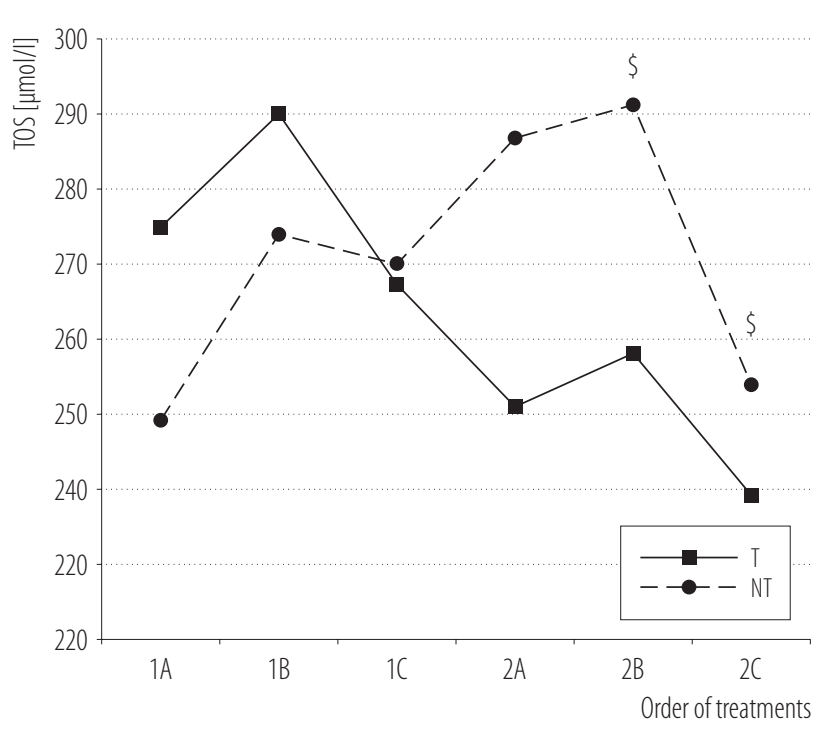

Explanations as in Figure 1.

${ }^{\$} \mathrm{p}<0.05$ significant changes in the non-training group between $2 \mathrm{~B}$ and $2 \mathrm{C}$ measurements.

Figure 2. Changes in the plasma total oxidant status (TOS) in the training (T) and non-training groups (NT) during sauna baths, in the study on the influence of Finnish sauna baths on the concentrations of nitric oxide metabolites $\left(\mathrm{NO}_{\mathrm{x}}\right)$ and 3-nitrotyrosine $\left(\mathrm{NO}_{2}\right.$-Tyr) in relation to pro-oxidative and antioxidative status of 2 groups of healthy males

nuksela [19]. In the available literature, however, there are some inconsistencies regarding the influence of sauna baths on blood pressure, which most probably result from the types of cooling down methods used between thermal exposures [19,24,25].

The acclimation to high temperatures is evidenced by the fact that a significant increase in rectal temperature was observed in both groups of males (Table 2). This increase turned out to be smaller during the last bath, similar to the temperature measured before the last entry into the sauna chamber [21].

The primary objective of this study was to determine whether, and to what extent, a series of Finnish sauna baths contributes to the modification of the total pro-oxidative and antioxidative status, with specific attention paid to nitrosative stress. 


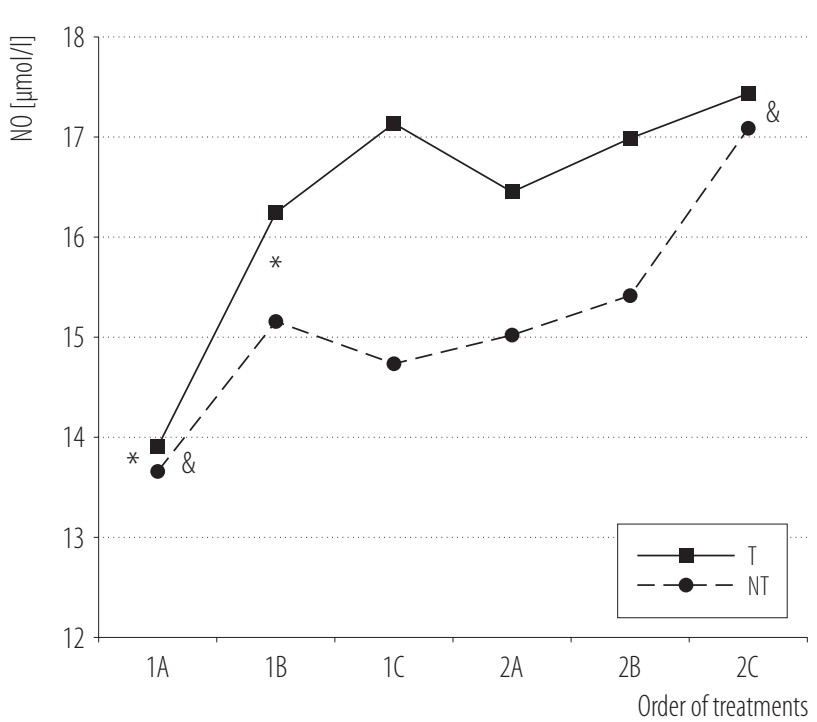

Explanations as in Figure 1.

$* p<0.05$ significant changes in the training and non-training groups between $1 \mathrm{~A}$ and $1 \mathrm{~B}$ measurements.

${ }^{\&} \mathrm{p}<0.05$ significant changes in the training and non-training groups between $1 \mathrm{~A}$ and $2 \mathrm{C}$ measurements.

Figure 3. Changes in the nitric oxide (NO) levels in the training (T) and non-training groups (NT) during sauna baths, in the study on the influence of Finnish sauna baths on the concentrations of nitric oxide metabolites $\left(\mathrm{NO}_{\mathrm{x}}\right)$ and 3-nitrotyrosine $\left(\mathrm{NO}_{2}\right.$-Tyr) in relation to pro-oxidative and antioxidative status of 2 groups of healthy males

Under the influence of dry sauna baths, the pro-oxidative/ antioxidative balance was disrupted in both study groups, which manifested itself in a significant decrease in the total antioxidative status of plasma. The cause of oxidative stress could be the inadequate blood supply - reperfusion of internal organs during hyperthermia. The results are consistent with the ones published earlier by Pilch et al. [26]. It was shown that various forms of overheating of the human body (both passive and active) led to a prooxidative/antioxidative imbalance. In the study by Pilch et al. [26], physically active men had a higher level of antioxidative status and a lower level of plasma peroxidation products, compared to untrained men, while in the present study, only the second difference was observed. Different responses to the thermal stimulus used were indicated

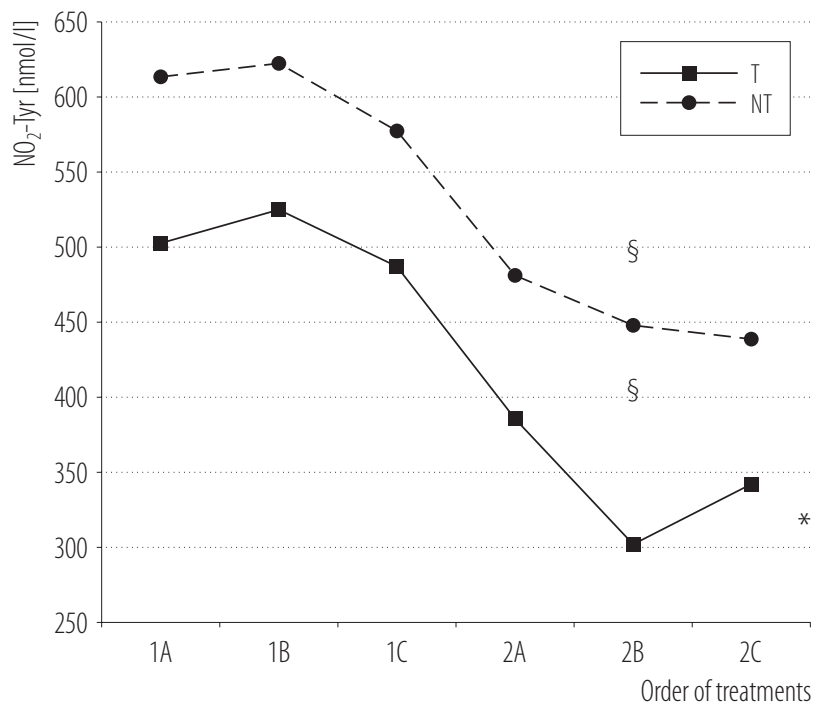

Explanations as in Figure 1.

${ }^{\S} \mathrm{p}<0.05$ significant changes in the training and non-training groups between $1 \mathrm{~A}$ and $2 \mathrm{~A}$ measurements.

$* \mathrm{p}<0.05$ significant changes in the training groups between $2 \mathrm{~A}$ and 2B measurements.

Figure 4. Changes in the 3-nitrotyrosine ( $\mathrm{NO}_{2}$-Tyr) levels in the training (T) and non-training groups (NT) during sauna baths, in the study on the influence of Finnish sauna baths on the concentrations of nitric oxide metabolites $\left(\mathrm{NO}_{\mathrm{x}}\right)$ and 3-nitrotyrosine $\left(\mathrm{NO}_{2}\right.$-Tyr) in relation to pro-oxidative and antioxidative status of 2 groups of healthy males

in the subjects. In the men from the T group, a significant level of TOS was demonstrated after a series of sauna treatments. This observation confirms the adaptive role of physical training $[22,23]$.

No statistically significant differences were observed between the study groups, as far as the concentration of 3-nitrotyrosine in plasma is concerned, before starting thermal treatments in the sauna. The series of sauna baths contributed to a decrease in the level of this indicator in both groups, whereas in the group of training males, a further significant decrease was observed after the 10th treatment. The obtained study results show a significant involvement of thermal therapy in a long-term decrease in nitrosative stress, which was shown by the decrease in the concentration of 3-nitrotyrosine in the training group, measured 
Table 3. Changes in the volume of plasma $(\% \Delta \mathrm{PV})$ during sauna treatments in the study on the influence of Finnish sauna baths on the concentrations of nitric oxide metabolites $\left(\mathrm{NO}_{\mathrm{x}}\right)$ and 3-nitrotyrosine $\left(\mathrm{NO}_{2}\right.$-Tyr) in relation to pro-oxidative and antioxidative status of 2 groups of healthy males

\begin{tabular}{|c|c|c|}
\hline \multirow[t]{2}{*}{ Plasma volume } & \multicolumn{2}{|c|}{$\begin{array}{c}\text { Participants } \\
(\mathrm{N}=20) \\
{[\%]} \\
(\mathrm{M} \pm \mathrm{SD})\end{array}$} \\
\hline & $\begin{array}{l}\text { training group } \\
\quad(\mathrm{N}=10)\end{array}$ & $\begin{array}{l}\text { non-training group } \\
\qquad(\mathrm{N}=10)\end{array}$ \\
\hline$\% \Delta \mathrm{PV} 1$ (after the first treatment) & $-8.91 \pm 3.85$ & $-7.31 \pm 2.52$ \\
\hline$\% \Delta \mathrm{PV} 2$ (after the last treatment) & $-11.17 \pm 2.54^{* * \#}$ & $-7.91 \pm 1.64$ \\
\hline$\% \Delta \mathrm{PV} 3$ (after the series of treatments) & $7.04 \pm 3.78$ & $4.27 \pm 4.13$ \\
\hline
\end{tabular}

** Significance of differences between the training and non-training groups, with $\mathrm{p}<0.01$ (the Mann-Whitney U test).

\# Significance of differences between $\% \Delta \mathrm{PV} 1$ and $\% \Delta \mathrm{PV} 2$ (the Wilcoxon test).

after the 10th treatment, in relation to the baseline values; a decrease of $32.1 \%$ in the training group, and of $28.3 \%$ in the non-training group; $\mathrm{p}<0.05$ ) (Figure 4).

The influence of hyperthermia on the level of 3-nitrotyrosine in rats was the subject of studies by Selsby et al. [27,28]. The quoted authors conducted 2 independent experiments concerning the influence of oxidative stress taking place during the immobilization of a muscle [27] and during the mobilization of a muscle after initial immobilization [28]. Both the immobilization itself and the mobilization of the muscle after immobilization caused a significant increase in the concentration of 3-nitrotyrosine in the blood of rats from the groups not subjected to hyperthermia, in comparison to the control group not subjected to any treatments. In the animals in which concurrent thermal therapy was used, it was observed that the level of 3-nitrotyrosine was close to the values observed in control groups, i.e., significantly lower than in the groups in which hyperthermia was not applied.

The NO plasma levels obtained in this study were within the reference range established for healthy adults $[29,30]$. Several authors have reported that the NO produced by eNOS is involved in the process of redistribution of blood during thermal treatments [31-33]. This is confirmed by the results of an experiment conducted on hamsters (subjected to thermal sauna therapy in temperature of $60^{\circ} \mathrm{C}$ for a period of 4 weeks), which showed an increase in the amount of NO in the blood serum of the animals subjected to the treatments, in comparison to the control group. Additionally, an increase in the expression of the eNOS enzyme, and a lack of changes in the expression of the iNOS enzyme, were shown. This indicates that the activity of eNOS contributed to the increase in the amount of NO after thermal therapy [34]. Zinchuk and Zhadzko [14], studying the influence of a series of Finnish sauna baths in temperature of $85-90^{\circ} \mathrm{C}, 1 /$ week for 5 months, on the level of NO in the blood serum of training males, observed an increased concentration of this parameter by $26.2 \%$ after the first treatment at the beginning of the study, and by $25.5 \%$ after the last treatment, in comparison with the values recorded before every treatment [11,35]. Similar to the non-training group of males taking part in similar studies, in comparison with the baseline values, the concentration of NO increased by $20.1 \%$ after the first treatment and by $17.1 \%$ after the last treatment [35].

In the presented study, an increase in the concentration of $\mathrm{NO}_{\mathrm{x}}$ was observed after the first sauna bath in the $\mathrm{T}$ and NT groups, of $16.9 \%$ and $11.0 \%$, respectively, togeth- 
er with an increase of $25 \%$ in both groups of males after the whole series of sauna baths, in relation to the values recorded before the study (Figure 3). The observed results confirm that thermal baths in the sauna contribute to an increased bioavailability of $\mathrm{NO}$ in peripheral blood. This increase can be the result of 2 mechanisms:

1) an increased production of $\mathrm{NO}$ due to stimulation of the activity of NOS, and/or

2) an inhibition of the process of deactivation of the NO molecule, which takes place when it reacts with the superoxide radical anion, in the context of increased oxidative stress [36,37].

The decrease in systolic blood pressure in the male subjects during the last sauna treatment, in comparison with the first bath, which was observed in this study, can be a sign of increased vasodilatation and an increased blood flow during exposure to a thermal stimulus. This effect can be a reaction to the increased amount of $\mathrm{NO}$ observed in venous blood after a series of treatments, despite the fact that the analysis of Spearman's rank correlation between the decrease in the value of systolic blood pressure and the increase in the concentration of $\mathrm{NO}_{\mathrm{x}}$ did not reveal statistical significance. The observed tendency requires further investigation.

Harris et al. [38], in their study conducted on isolated animal tissues, showed that not only mechanical force influencing vessel endothelium in the form of shear force, due to an increased blood flow, was a stimulus influencing eNOS activity, but the thermal stimulus itself also caused an increase in the expression of eNOS and increased the release of $\mathrm{NO}$ in vessel endothelium [39]. In these studies, after Finnish sauna treatments, together with the increase in the concentration of NO, as mentioned before, a simultaneous decrease in the concentration of 3-nitrotyrosine was observed. Despite the fact that the performed analysis of Spearman's rank correlation did not show any relationship between the increase in the concentration of NO and the decrease in the concentration of 3-nitrotyrosine in the blood plasma of the male subjects, it can be presumed that the increased bioavailability of NO in the blood plasma of the male subjects was caused by a long-term decrease in oxidative stress in the organism, and the increase in the activity of eNOS enzyme, as indicated by the increase in the amount of NO in plasma after the first treatment. The obtained results require confirmation with other study models.

\section{CONCLUSIONS}

Both a single bath in the Finnish sauna and a series of 10 baths in a group of runners and people with moderate physical activity disrupt the pro-oxidative/antioxidative balance, which manifests itself in a significant decrease in the total antioxidative status of plasma, on the one hand. On the other hand, it induces an adaptive mechanism leading to an increase in $\mathrm{NO}$ availability and a decrease in the concentration of nitrosative stress markers. The lower values of systolic blood pressure observed in the studied males during the last bath, in comparison with the first treatment, could be explained as resulting from an increased amount of $\mathrm{NO}_{\mathrm{x}}$ in peripheral blood, and thus, improved vasodilatation.

The authors suggest that this kind of treatment may be useful in the biological renewal of runners as well as in subjects with moderate physical activity. In both groups, it contributes to the improvement in the pro-oxidative/antioxidative balance. The increase in the production of NO may contribute to a better vascular relaxation and blood flow in vessels, in both training and non-training people, but more favorable changes occur in the former group. Therefore, the authors suppose that such treatments may have a preventive effect on cardiovascular diseases.

\section{Study limitations}

A limitation present in the study design is the fact that no diet analysis was conducted, which would provide more detailed information concerning the NO plasma levels. Nevertheless, the subjects were asked not to change their diet dur- 
ing the study period, which allowed the authors to assume no impact of the diet on the results of performed tests.

\section{REFERENCES}

1. Dreißigacker U, Wendt M, Wittke T, Tsikas D, Maassen N. Positive correlation between plasma nitrite and performance during high-intensive exercise but not oxidative stress in healthy men. Nitric Oxide. 2010;23(2):128-35, https://doi. org/10.1016/j.niox.2010.05.003.

2. Beckman JS, Koppenol WH. Nitric oxide, superoxide, and peroxynitrite: the good, the bad, and ugly. Am J PhysiolCell Physiol. 1994;271(5):C1424-37, https://doi.org/10.1152/ ajpcell.1996.271.5.C1424.

3. Salvemini D, Misko TP, Masferrer JL, Seibert K, Currie $\mathrm{MG}$, Needleman P. Nitric oxide activates cyclooxygenase enzymes. Proc Natl Acad Sci USA. 1996;90:7240-4.

4. Tarpey M, Fridovich I. Methods of detection of vascular reactive species. Nitric oxide, superoxide, hydrogen peroxide, and peroxynitrite. Circ Res. 2001;89:224-36, https://doi.org/ 10.1161/hh1501.094365.

5. Stepnik M. Molecular aspects of toxic effects of nitric oxide. Med Pr. 2001;52(5):375-81.

6. Biro S, Masuda A, Kihara T, Tei C. Clinical implications of thermal therapy in lifestyle-related diseases. Exp Biol Med (Maywood). 2003;228(10):1245-9.

7. Scoon GS, Hopkins WG, Mayhew S, Cotter JD. Effect of post-exercise sauna bathing on the endurance performance of competitive male runners. J Sci Med Sport. 2007;10(4):25962, https://doi.org/10.1016/j.jsams.2006.06.009.

8. Prystupa T, Wołyńska A, Ślężýski J. The effects of Finnish sauna on hemodynamics of the circulatory system in men and women. J Hum Kinet. 2009;22:61-8, https://doi.org/10.2478/ v10078-009-0024-3.

9. Blum N, Blum A. Beneficial effects of sauna bathing for heart failure patients. Exp Clin Cardiol. 2007;12(1):215-25.

10. Crinnion WJ. Sauna as a valuable clinical tool for cardiovascular, autoimmune, toxicant-induced and other chronic health problems. Altern Med Rev. 2011;16(3):215-25.
11. Hussain J, Cohen M. Clinical effects of regular dry sauna bathing: a systematic review. Evid Based Complement Alternat Med. 2018;1857413, https://doi.org/10.1155/2018/1857413.

12. Sutkowy P, Woźniak A, Boraczyński T, Mila-Kierzenkowska C, Boraczyński M. The effect of a single Finnish sauna bath after aerobic exercise on the oxidative status in healthy men. Scan J Clin Lab Invest. 2014;74:89-94, https://doi.org/10. 3109/00365513.2013.860616.

13. Livingston R. Medical risks and benefits of the sweat lodge. J Altern Comlement Med. 2010;16:617-9, https://doi.org/10. 1089/acm.2008.0381.

14. Zinchuk V, Zhadzko D. Sauna effect on blood oxygen transport and prooxidant-antioxidant balance in athletes. Sports Med J/Med Sportiva. 2012;8(3):1883-9.

15. Craig CL, Marshall AL, Sjostrom M, Bauman AE, Booth ML, Ainsworth BE, et al. International physical activity questionnaire: 12 -country reliability and validity. Med Sci Sports Exerc. 2003;35(8):1381-95, https://doi.org/10.1249/ 01.MSS.0000078924.61453.FB.

16. Slaughter MH, Lohman TG, Boileau R, Horswill CA, Stillman RJ, Van Loan MD, et al. Skinfold equations for estimation of body fatness in children and youth. Hum Biol. 1988;60(5):709-23.

17. Johansen LB, Videbæk R, Hammerum M, Norsk P. Underestimation of plasma volume changes in humans by hematocrit/hemoglobin method. Am J Physiol. 1998;274(1):R12630, https://doi.org/10.1152/ajpregu.1998.274.1.R126.

18. Kraemer RR, Brown BS. Alterations in plasma-volumecorrected blood components of marathon runners and concomitant relationship to performance. Eur J Appl Physiol Occup Physiol. 1986;55(6):579-84.

19. Hannuksela ML, Ellahham S. Benefis and risk of sauna bathing. Am J Med. 2001;110(2):118-26, https://doi.org/10.1016/ S0002-9343(00)00671-9.

20. TalebipourB, RodriguesL,Moreira M.Effects of sauna on cardiovascular and lifestyle-related diseases. Rev Bras Med Esporte. 2006;12(4), https://doi.org/10.1590/S1517-8692200600 0400010. 
21. Leppäluoto J, Tuominen M, Väänänen A, Karpakka J, Vuori J. Some cardiovascular and metabolic effects of repeated sauna bathing. Acta Pysiol Scand. 1986;128(1):77-81, https:// doi.org/10.1111/j.1748-1716.1986.tb07952.x.

22. Żychowska M, Półrola P, Chruściński G, Zielińska J, GóralPółrola J. Effects of sauna bathing on stress-related genes expression in athletes and non-athletes. Ann Agric Environ Med. 2017;24(1):104-7, https://doi.org/10.5604/123219 66.1233977.

23. Żychowska M, Nowak-Zaleska A, Chruściński G, Zaleski R, Mieszkowski J, Niespodziński B, et al. Association of High Cardiovascular Fitness and the Rate of Adaptation to Heat Stress. Biomed Res Int. 2018;2018:1685368, https://doi. org/10.1155/2018/1685368.

24. Kukkonen-Harjula K, Kauppinen K. Health effects and risk of sauna bathing. Int J Circumpolar. 2006;65(3):195-205.

25. Sawicka A, Brzostek T, Kowalski R. Effects of sauna bath on the cardiovascular system. Med Rehabil. 2007;11(1):15-22.

26. Pilch W, Szygula Z, Tyka AK, Palka T, Tyka A, Cison T, et al. Disturbances in pro-oxidant-antioxidant balance after passive body overheating and after exercise in elevated ambient temperatures in athletes and untrained men. PLoS One. 2014;9(1): e85320, https://doi.org/10.1371/journal.pone.0085320.

27. Selsby JT, Rother S, Tsuda S, Pracash O, Quindry J, Dodd SL. Intermittent hyperthermia enhances skeletal muscle regrowth and attenuates oxidative damage following reloading. J Appl Physiol. 2007;102(4):1702-7, https:/doi. org/10.1152/japplphysiol.00722.2006.

28. Selsby JT, Dodd SL. Heat treatment reduces oxidative stress and protects muscle mass during immobilization. Am J Physiol Regul Integr Comp Physiol. 2005;289(1):R134-9, https:// doi.org/10.1152/ajpregu.00497.2004.

29. Ghasemi A, Zahedi Asl S, Mehrabi Y, Saadat N, Azizi F. Serum nitric oxide metabolite levels in a general healthy population: relation to sex and age. Life Sci. 2008;83(9-10):32631, https://doi.org/10.1016/j.lfs.2008.06.010.

30. Ghasemi A, Zahediasl S, Azizi F. Reference values for serum nitric oxide metabolites in an adult population. Clin
Biochem 2010;43(1-2):89-94, https://doi.org/10.1016/j.clinbiochem.2009.09.011.

31. Fujita S, Ikeda Y, Miyata M, Shinsato T, Kubozono T, Kuwahata $\mathrm{S}$, et al. Effect of Waon therapy on oxidative stress in chronic heart failure. Circ J. 2011;75(2):348-56, https://doi. org/10.1253/circj.CJ-10-0630.

32. Imamura M, Biro S, Kihara T, Yoshifuku S, Takasaki K, Otsuji Y, et al. Repeated thermal therapy improves impaired vascular endothelial function in patients with coronary risk factors. J Am Coll Cardiol. 2001;38(4):1083-8, https://doi. org/10.1016/S0735-1097(01)01467-X.

33. Ohori T, Nozawa T, Ihori H, Shida T, Sobajima M, Matsuki A, et al. Effect of repeated sauna treatment on exercise tolerance and endothelial function in patients with chronic heart failure. Am J Cardiol. 2012;109(1):100-4, https://doi. org/10.1016/j.amjcard.2011.08.014.

34. Ikeda Y, Biro S, Kamogawa Y, Yoshifuku S, Eto H, Orihara $\mathrm{K}$, et al. Repeated sauna therapy increases arterial endothelial nitric oxide synthase expression and nitric oxide production in cardiomyopathic hamsters. Circ J. 2005;69(6): 722-9, https://doi.org/10.1253/circj.69.722.

35. Zinchuk V, Zhadzko D. The effect of a sauna on blood oxygen transport and the prooxidant-antioxidant balance in untrained subjects. Human Physiol. 2012;38(5):548-54, https:// doi.org/10.1134/S0362119712030152.

36. Green DJ, Maiorana A, O'Driscoll G, Taylor R. Effect of exercise training on endothelium-derived nitric oxide function in humans. J Physiol. 2004;561(1):1-25; https://doi. org/10.1113/jphysiol.2004.068197.

37. Higashi Y, Yoshizumi M. Exercise and endothelial function: Role of endothelium-derived nitric oxide and oxidative stress in healthysubjectsandhypertensivepatients.PharmacolTher.2004; 102(1):87-96,https://doi.org/10.1016/j.pharmthera.2004.02.003.

38. Harris MB, Blackstone MA, Ju H, Venema VJ, Venema RC. Heat-induced increases in endothelial NO synthase expression and activity and endothelial NO release. Am J Physiol Heart Circ Physiol. 2003;285(1):H333-40, https://doi. org/10.1152/ajpheart.00726.2002. 
39. McCarty MF, Barroso-Aranda J, Contreras F. Regular thermal therapy may promote insulin sensitivity while boosting expression of endothelial nitric oxide synthase-effects comparable to those of exercise training. Med Hypotheses. 2009;73(1):103-5, https://doi.org/10.1016/j.mehy.2008. 12.020 .

This work is available in Open Access model and licensed under a Creative Commons Attribution-NonCommercial 3.0 Poland License - http://creativecommons.org/ licenses/by-nc/3.0/pl/deed.en. 